\title{
The Order of the Engineer: A Recognition of an Engineer's Obligation to Society
}

\author{
Judy L. Cezeaux \\ College of Engineering and Applied Sciences, Arkansas Tech University \\ Board of Governors, Order of the Engineer
}

\begin{abstract}
The Order of the Engineer is an organization whose express purpose is to promote professionalism in engineering practice by instilling in its members an obligation to the ethical practice of engineering. This paper will describe the history of the Order of the Engineer, its governance structure and membership requirements, and components of the induction ceremony. Information will also be provided on how to start a link (chapter) in academic and professional organizations.
\end{abstract}

\section{Keywords}

Order of the Engineer, ethics, obligation, professional paper

\section{History of the Order}

The Order of the Engineer in the United States has its roots in the Corporation of the Seven Wardens, a Canadian organization incorporated in 1935 which administers The Ritual of the Calling of an Engineer. The organization was founded upon the urging of Professor H. E. T. Haultain of the University of Toronto who, in 1922 at the Annual Professional Meeting of the Engineering Institute of Canada, discussed the need to instill a sense of ethics into engineering graduates. Professor Haultain enlisted the assistance of Rudyard Kipling to develop the Obligation and Ceremony Ritual. The first ceremony was held at the University Club in Montreal on April 25, 1925. Ceremonies inducting both engineering graduates and working engineering professionals are conducted by Camps on behalf of the Corporation of the Seven Wardens. At the ceremony, Canadian inductees receive an iron ring to symbolize their commitment to their obligation. [1]

Although the founding documents of the Corporation of the Seven Wardens prevented expansion of the Canadian Calling to other countries, in the 1950s there were discussions between the Corporation and professional engineers from the Ohio Society of Professional Engineers (OSPE) that led to two members of the OSPE being inducted into the Canadian Calling in 1962. The momentum for a US version of the Canadian Calling intensified in the 1960s as members of the OSPE formed a committee to establish a similar organization in the US. The committee enlisted the assistance of the deans of the Ohio colleges of engineering and on June 4, 1970, the first members of the Order of the Engineer were inducted at a ceremony at Cleveland State University. As with the Canadian Calling, the Order of the Engineer ceremony included the reciting of an Obligation and the receipt of a ring to be worn on the little finger of the working hand. Unlike the rings of the Canadian Calling, the rings worn by Order of the Engineer members are stainless steel. [1] The Obligation encourages engineers to reflect on the work of 
their predecessors and to uphold their commitment to use their knowledge for the betterment of society. [2]

\section{Order of the Engineer Governance Structure}

The Order of the Engineer is administered by a Board of Governors and an Executive Director, subject to the Order's Code of Regulations. These regulations stipulate that the Board of Governors is to be made of not less than eight and not more than twenty-one governors, who each serve a three-year term with re-election possible [3]. Currently, there are twenty Governors whose professional positions include serving as engineering educators or practicing engineers, spanning a wide range of engineering disciplines [4]. The Board of Governors meets annually, usually in Phoenix, AZ, the location of the Order's headquarters.

The Order of the Engineer is made up of Links (chapters) at universities and professional engineering organizations. Links maintain communications with the Order's headquarters through a Link Liaison in their organization. In addition, one of the members of the Board of Governors serves as an advisor to each Link to assist with ceremony logistics, including participation as one of the Order members that is required to be present at the induction ceremony, if needed.

\section{Membership and Induction Ceremony}

Membership in the Order of the Engineer is limited to the following individuals: 1) graduates of programs accredited by the Engineering Accreditation Commission (EAC) of ABET, Inc., 2) seniors within one academic year of graduation from an ABET EAC accredited program, 3) graduate students in ABET EAC accredited programs or in graduate engineering programs in departments with an ABET EAC accredited undergraduate degree, 4) licensed professional engineers, 5) members of the Canadian Calling, and 6) individuals with noteworthy accomplishments in engineering [2]. Graduates of engineering technology programs are not, in general, eligible for membership.

Each Link is responsible for the planning and execution of induction ceremonies. The ceremony is often proximate to graduation ceremonies at university Links or during an annual meeting for Links at professional organizations. The ceremonies are open to the public. All induction ceremonies must follow the guidelines set forth by the Board of Governors [5], but there is significant flexibility in the conduct of the ceremony. At least two members of the Order must be present for the ceremony, but it is preferable to have at least three members in attendance. Links may request the presence of Governors to fulfill this minimum requirement and these are provided at no cost to the Link. Minimally, the induction ceremony must contain remarks on the history and significance of the Order and the significance of the ring. Candidates then verbally accept the Obligation and receive their certificate and ring. Optional components of the ceremony may include presentations on engineering ethics or presentation of a professional license. The ceremony should instill in inductees a sense of pride in the engineering profession and remind these engineers entering the field or achieving licensure of their obligation to serve humanity. 
Due to the COVID-19 pandemic, the Board of Governors developed a ceremony protocol for virtual induction ceremonies. Virtual ceremonies have similar minimum requirements as traditional face-to-face ceremonies, but only one Order member must be present at a virtual ceremony [5].

Academic institutions or professional engineering societies wishing to establish a Link at their organization should contact the Order of the Engineer headquarters. To ensure continuity of the Link, the organization should appoint a Link Liaison that can provide consistent communications with the Order's headquarters and the Governor assigned to the Link. At universities, Link Liaisons are often staff members within the office of the dean or associate dean of engineering.

\section{Conclusion}

As technology continues to advance and global challenges arise, it remains paramount that engineers act ethically in their professional work. The Order of the Engineer is an organization whose stated purpose is to foster a sense of pride in the engineering profession and to promote the ethical practice of engineering in new engineering graduates and engineering professionals. Induction into the Order can serve as a reminder of the engineer's accountability to society. Members of the Order are recognizable by the wearing of a stainless steel ring on the little finger of the working hand and these individuals have taken an Obligation to recognize their responsibilities to society as they undertake their professional duties.

\section{References}

[1] K. A. Wedel, "Origins," in The Obligation: A History of the Order of the Engineer, Bloomington, IN, USA: AuthorHouse, 2012, pp. 1-24.

[2] K. A. Wedel, "Appendix A: The Obligation," in The Obligation: A History of the Order of the Engineer, Bloomington, IN, USA: AuthorHouse, 2012, pp. 75-78.

[3] "Order of the Engineer Code of Regulations." https://order-of-the-engineer.org/wpcontent/uploads/2019/12/Code-of-Regulations-10-19-2019-4.pdf (Accessed: Jul 26, 2021).

[4] "Order of the Engineer Board of Governors." https://order-of-theengineer.org/directories/board-of-governors/ (Accessed: Jul 26, 2021)

[5] The Order of the Engineer, Inc., "Manual for Conducting Order of the Engineer Induction Ceremonies." https://order-of-the-engineer.org/wp-content/uploads/2020/12/CleanVersion-Order-of-the-Eng-Link-Manual-updated-10-17-2020-2.pdf (Accessed: Aug 2, 2021)

\section{Judy L. Cezeaux}

Judy L. Cezeaux is Dean of Engineering and Applied Sciences and Professor of Engineering at Arkansas Tech University. She received her B.S. in mechanical engineering from Carnegie Mellow University and Ph.D. in biomedical engineering from Rensselaer Polytechnic Institute. Prior to her appointment at Arkansas Tech, she was Professor and Chair of Biomedical Engineering at Western New England University. She has also served as a Senior Staff Fellow at the National Institute for Occupational Safety and Health as well as a faculty member at the University of Tennessee, Knoxville. She has been a member of the Board of Governors of the Order of the Engineer since 2019. 